\title{
Efektivitas pengolahan limbah cair hotel dan implementasi keputusan Menteri Lingkungan Hidup nomor 52/menlh/10/1995 tentang baku mutu limbah cair bagi kegiatan hotel di Kota Pekanbaru
}

\author{
Syafri Boy ${ }^{1}$, Aras Mulyadi ${ }^{2}$, Sukendi ${ }^{2}$ \\ ${ }^{1}$ Pranata Ahli Pratama Laboratorium Mutu Lingkungan Budidaya Fakultas Perikanan dan Ilmu Kelautan \\ Universitas Riau \\ ${ }^{2}$ Dosen Pascasarjana Ilmu Lingkungan Program Pascasarjana
}

\begin{abstract}
This research aims to determine the effectiveness of the treatment of waste water hotel and see Implemantation Decree of the Minister of Environment No.52/MENLH/10/1995 concerning the Waste water Quality Hotel by five-star hotel in the city of Pekanbaru. The method used in this research is the survey and interview. Based on the analysis we found that the rate of decrease in the content of pollutants in the waste water hotel in reducing the content of pollutants in the waste water for parameters BOD, COD, TSS and pH respectively 72\%,75\%,25\% and 16\%. IPL Cability levels in the lower levels of waste water sample parameters for the parameters BOD, COD, TSS and pH respectively 60.0\%, 30.0\%, 50.0\% and 87.5\%. IPLC analysis results in Pekanbaru compared with the Waste water Quality Standard Hotel, pollutant levels are still above the environmental quality standards.
\end{abstract}

\section{Keywords: Pekanbaru, wastewater, effectiveness, processing, hotel}

Usaha perhotelan didaerah perkotaan dan kawasan pariwisata akan menghasilkan berbagai jenis limbah baik dalam bentuk padat maupun cair.Dibangunnya hotel dikawasan pemukiman warga akan berdampak pada masyarakat di sekitar hotel terutama buangan limbah cair. Limbah cair dari aktivitas perkotaan berupa air buangan (efluen) operasional harian dari dapur, MCK, laundry dan kegiatan lainnya seperti Biological Oxygen Demand (BOD), Chemical Oxygen Demand (COD), Total Suspended Solid (TSS) dan Potential of Hydrogen $(\mathrm{pH})$; bila diatas baku yang telah ditetapkan dibuang ke lingkungan pemukiman mengakibatkan terganggunya keseimbangan ekologi bahkan menyebabkan kematian organisme akuatik. Sumur-sumur warga juga akan tercemar akibat rembesan limbah cair di dalam tanah. (Agul, 2012).

Dari data Dinas Kebudayaan dan Pariwisata Kota Pekanbaru, terdapat 138 hotel di kota Pekanbaru diantaranya 21 hotel berbintang 3, 4 dan 5. Rata-rata lokasi hotel berada di pemukiman warga. Wahana Lingkungan Hidup dalam kilasriaublogspot.com (2013) mengatakan, limbah cair yang dihasilkan dari kegiatan industri hotel perlu diolah secara tepat agar tidak menimbulkan resiko terhadap lingkungan dan kesehatan masyarakat sekitar.Banyaknya hotel yang berdiri di kota Pekanbaru telah menimbulkan kekhawatiran tersendiri bagi warga, seperti dampak dari penanganan limbah yang tak tertangani. Seharusnya limbah-limbah yang dihasilkan dalam aktifitasnya itu harus ada Upaya Pengelolaan Lingkungan (UKL) dan Upaya Pemantauan Lingkungan (UPL) yang secara berkala dilakukan Badan Lingkungan Hidup (BLH).

Banyak instalasi pengolahan limbah cair (IPLC) hotel yang belum dapat berfungsi secara efektif. Secara fisik bangunan instalasi tersebut sudah ada, tetapi dalam pengelolaannya belum bekerja secara optimal (Yogi, 2014) Menurut Keputusan Menteri Negara Lingkungan Hidup No. 52/MENLH/10/1995 Tentang Baku Mutu Limbah Cair Bagi Kegiatan Hotel, limbah cair hotel adalah limbah dalam bentuk cair yang dihasilkan oleh kegiatan hotel yang dibuang ke lingkungan dan diduga dapat menurunkan kualitas lingkungan.

Tujuan penelitian ini adalah mengetahui efektivitas pengolahan limbah cair hotel dan melihat analisis implemantasi Keputusan Menteri Negara Lingkungan Hidup No. 52/MENLH/10/1995 tentang Baku Mutu Limbah Cair Hotel oleh hotel berbintang di kota Pekanbaru. 


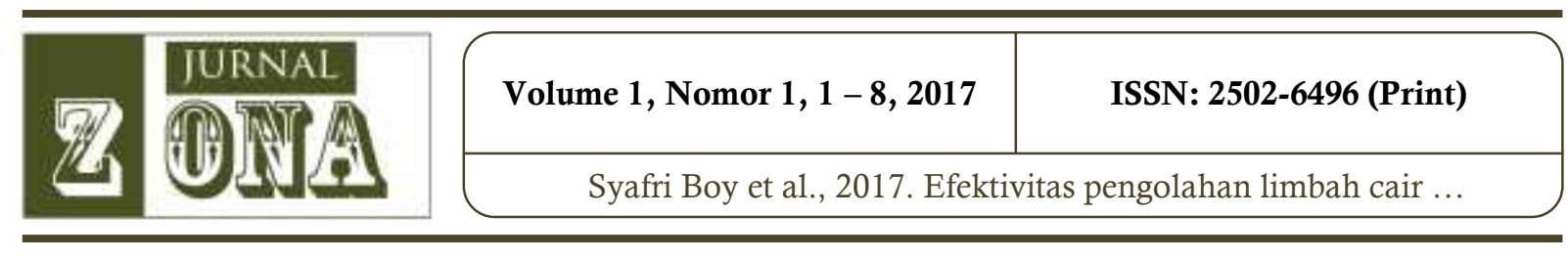

\section{METODE PENELITIAN}

Penelitian ini dilakukan pada bulan Januari sampai dengan Maret 2015, pada hotel berbintang 3, 4 dan 5 yang telah ditetapkan di Kota Pekanbaru. Metode yang digunakan adalah metoda survey dan wawancara. Jumlah sampel dalam penelitian ini adalah 10 hotel yang ditetapkan dengan metode stratified random sampling (Singarimbun, 2011). Jumlah sampel hotel yang dimaksud dapat dilihat pada Tabel 1.

Tabel 1. Jumlah Sampel berdasarkan Jenis Hotel.

\begin{tabular}{ccc}
\hline Hotel & Rumus Penetapan Sampel & Jumlah sampel \\
\hline Bintang 3 kode A1 s/d A6 & $(12: 21) \times 10=5,7$ & 6 hotel \\
Bintang 4 kode B1 s/d B3 & $(7: 21) \times 10=3,3$ & 3 hotel \\
Bintang 5 kode C1 & $(2: 21) \times 10=0,9$ & 1 hotel \\
& & 10 hotel \\
\hline
\end{tabular}

Parameter yang dianalisis berupa BOD, COD, TSS dan $\mathrm{pH}$. Metoda pengukuran kualitas air dalam penelitian ini menurut Standar Nasional Indonesia (SNI) seperti terlihat pada Tabel 2.

Tabel 2. Parameter lingkungan yang diukur, bahan dan alat serta metoda yang digunakan dalam penelitian

\begin{tabular}{|c|c|c|c|c|c|}
\hline No & Parameter & Satuan & Bahan \& Alat & Metode & Analisis \\
\hline 1 & $\mathrm{BOD}_{5}$ & $\mathrm{mg} / 1$ & $\begin{array}{l}\text { Air sampel, } \mathrm{MnSO}_{4} \text {, } \\
\text { alkalin, } \mathrm{H}_{2} \mathrm{SO}_{4} \text {, amilum, } \\
\text { thiosulaf, botol winkler, } \\
\text { erlenmeyer, botol inkubasi, } \\
\text { buret, almunium foil. }\end{array}$ & $\begin{array}{l}\text { SNI-Winkler } \\
\text { Iodometri }\end{array}$ & Laboratorium \\
\hline 2 & COD & $\mathrm{mg} / 1$ & $\begin{array}{l}\text { Air sampel, } \mathrm{K}_{2} \mathrm{Cr}_{2} \mathrm{O}_{7}, \\
\mathrm{H}_{2} \mathrm{SO}_{4} \text {, larutan FAS, } \\
\text { larutan blanko, aquades, } \\
\text { pipet tetes, tabung } \\
\text { erlenmeyer }\end{array}$ & $\begin{array}{l}\text { SNI- } \\
\text { Titrimetrik }\end{array}$ & Laboratorium \\
\hline 3 & TSS & $\mathrm{mg} / 1$ & $\begin{array}{l}\text { Air sampel Oven, gelas } \\
\text { ukur, pompa vakum, hot } \\
\text { plate, almunium foil, } \\
\text { timbangan analitik }\end{array}$ & $\begin{array}{l}\text { SNI- } \\
\text { Gravimetrik }\end{array}$ & Laboratorium \\
\hline 4 & $\mathrm{pH}$ & & Air sampel, $\mathrm{pH}$ meter & pHmetri & Laboratorium \\
\hline
\end{tabular}

Analisis data dilakukan secara deskriptif dengan menyajikan data kedalam bentuk tabel, menghitung persentase kemudian melakukan interpretasi. Untuk mengetahui teknik pengolahan limbah cair hotel, digunakan metoda wawancara terbuka dan observasi langsung ke masing-masing tempat instalasi pengolahan limbah cair (IPLC) mengenai sistem yang digunakan, berapa orang petugas operator dan tingkat kebocoran IPLC.

Untuk mengetahui efektivitas pengolahan limbah cair hotel berbintang di Kota Pekanbaru, merujuk pada Martono et al (2006), yakni dengan membandingkan kandungan polutan dari titik inlet IPLC dengan kandungan polutan di titik outlet IPLC terhadap empat parameter yaitu BOD, COD, TSS dan $\mathrm{pH}$. Keempat parameter ini dihitung tingkat penurunan kandungan polutan, tingkat kemampuan IPLC dalam menurunkan proporsi dan rata-rata hitungnya, presentase sampel yang memenuhi standar baku mutu dan tingkat efektivitas IPLC yang ada. Metoda yang digunakan adalah metoda komparatif yaitu membandingkan hasil analisis dengan standar baku mutu limbah hotel (Sugiyono, 2011) (Tabel 3).

Untuk melihat implementasi penerapan Keputusan Menteri Negara Lingkungan Hidup No. 52/MENLH/10/1995 tentang Baku Mutu Limbah Cair Bagi Kegiatan Hotel di kota Pekanbaru 


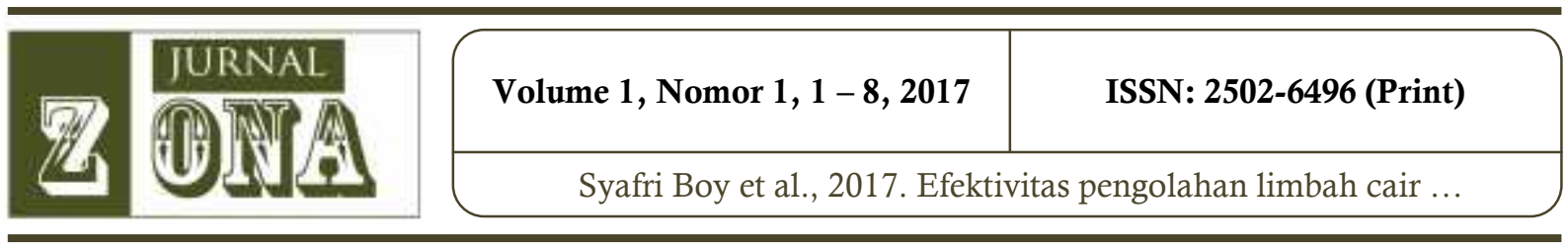

dianalisissecara deskriptif dengan metoda komparatif dengan melihat efektivitas IPLC yang dipersyaratkan apakah sudah memenuhi syarat $(\mathrm{M})$ atau tidak memenuhi syarat $(\mathrm{T})$ sesuai dengan Keputusan Menteri Negara Lingkungan Hidup No. 52/MENLH/10/1995 (Tabel 3).

Tabel 3. Baku mutu limbah cair bagi kegiatan hotel menurut Keputusan Menteri Negara Lingkungan Hidup No. 52/MENLH/10/1995

\begin{tabular}{cc}
\hline Parameter & Kadar Maksimum (mg/L) \\
\hline $\mathrm{BOD}_{5}$ & 30 \\
$\mathrm{COD}$ & 50 \\
$\mathrm{TSS}$ & 50 \\
$\mathrm{pH}$ & $6,0-9,0$ \\
\hline Sumber $:$ Keputusan Menteri Negara Lingkungan Hidup No. 52/MENLH/10/1995.
\end{tabular}

Sumber : Keputusan Menteri Negara Lingkungan Hidup No. 52/MENLH/10/1995.

\section{HASIL DAN PEMBAHASAN}

\section{Kualitas Limbah Cair Hotel di Kota Pekanbaru}

Data kualitas limbah cair hotel yang dianalisis dalam penelitian terdiri dari data oleh peneliti yang diambil dari inlet dan outlet IPLC dan data laporan tahunan outlet IPLC pihak hotel ke Badan Lingkungan Hidup Kota Pekanbaru pada tahun terakhiryaitu bulan Desember 2014. Kedua data outlettersebut dibandingkan dengan Keputusan Menteri Negara Lingkungan Hidup No. 52/MENLH/10/1995.Hasil analisis kandungan polutan limbah cair yang dilakukan peneliti dapat dilihat pada Tabel 4 .

Tabel 4.Data hasil analisis kandungan polutan limbah cair hotel di Kota Pekanbaru

\begin{tabular}{|c|c|c|c|c|c|c|c|c|}
\hline \multirow[b]{3}{*}{ Hotel } & \multicolumn{8}{|c|}{ Data Analisis Laboratorium } \\
\hline & \multicolumn{4}{|c|}{ Inlet } & \multicolumn{4}{|c|}{ Outlet } \\
\hline & $\begin{array}{l}\mathrm{BOD}_{5} \\
(\mathrm{mg} / \mathrm{L})\end{array}$ & $\begin{array}{c}\text { COD } \\
(\mathrm{mg} / \mathrm{L})\end{array}$ & $\begin{array}{c}\text { TSS } \\
(\mathrm{mg} / \mathrm{L})\end{array}$ & $\mathrm{pH}$ & $\begin{array}{l}\mathrm{BOD}_{5} \\
(\mathrm{mg} / \mathrm{L})\end{array}$ & $\begin{array}{c}\text { COD } \\
(\mathrm{mg} / \mathrm{L})\end{array}$ & $\begin{array}{c}\text { TSS } \\
(\mathrm{mg} / \mathrm{L})\end{array}$ & $\mathrm{pH}$ \\
\hline A1 & 200 & 360 & 54,36 & 5,21 & 20 & 42 & 48,36 & 6,30 \\
\hline A2 & 182 & 220 & 56,32 & 5,08 & 32 & 40 & 51,38 & 5,20 \\
\hline A3 & 84 & 120 & 61,34 & 6,01 & 4 & 8 & 56,34 & 6,38 \\
\hline A4 & 180 & 400 & 59,36 & 5,22 & 22 & 36 & 50 & 6,20 \\
\hline A5 & 320 & 680 & 82,20 & 5,11 & 30 & 72 & 54,40 & 5,90 \\
\hline A6 & 220 & 720 & 75,46 & 5,55 & 40,02 & 55,50 & 40,23 & 5,90 \\
\hline B1 & 56,22 & 90,28 & 52,38 & 4,8 & 12 & 24 & 56,38 & 6,22 \\
\hline B2 & 112 & 280 & 80,23 & 5,2 & 40,24 & 60 & 25 & 6,48 \\
\hline B3 & 90,40 & 158,3 & 90,24 & 5 & 60,66 & 80,45 & 20,40 & 6,54 \\
\hline $\mathrm{C} 1$ & 102 & 320 & 55,32 & 6,02 & 10 & 24 & 54,34 & 6,80 \\
\hline \multicolumn{5}{|c|}{ KepMen No. 52/MENLH10/1995 } & 30 & 50 & 50 & $6-9$ \\
\hline
\end{tabular}

Sumber
Keterangan : $A 1-A 6=$ Dotal Primer 2015
$3, B 1-B 3=$ Hotel bintang $4, C 1=$ hotel bintang 5

Pada inlet, hotel bintang 3 kadar $\mathrm{BOD}_{5}$ tertinggi $320 \mathrm{mg} / \mathrm{L}$ dan terendah $84 \mathrm{mg} / \mathrm{L}$, kadar COD tertinggi $680 \mathrm{mg} / \mathrm{L}$ dan terendah $120 \mathrm{mg} / \mathrm{L}$, kadar TSS tertinggi $82,2 \mathrm{mg} / \mathrm{L}$ dan terendah $54,36 \mathrm{mg} / \mathrm{L}$, kadar $\mathrm{pH}$ tertinggi 6,01 dan terendah 5,08. Hotel Bintang 4 kadar BOD $\mathrm{B}_{5}$ tertinggi $112 \mathrm{mg} / \mathrm{L}$ dan terendah $56,22 \mathrm{mg} / \mathrm{L}$, kadar COD tertinggi $280 \mathrm{mg} / 1$ dan terendah $90 \mathrm{mg} / \mathrm{L}$, kadar TSS tertinggi $90,24 \mathrm{mg} / 1 \mathrm{dan}$ terendah $52,38 \mathrm{mg} / \mathrm{L}$, kadar $\mathrm{pH}$ tertinggi 5 dan terendah 4,8. Hotel bintang 5 kadar $\mathrm{BOD}_{5} 320 \mathrm{mg} / \mathrm{L}$, COD $102 \mathrm{mg} / \mathrm{L}$, kadar TSS 55,32 mg/L dan pH 6,02.Sedangkan dibagian outlet, hotel bintang 3 kadar 
$\mathrm{BOD}_{5}$ tertinggi 40,02 mg/L terendah $4 \mathrm{mg} / \mathrm{L}$, kadar COD tertinggi $72 \mathrm{mg} / \mathrm{L}$ dan terendah $8 \mathrm{mg} / \mathrm{L}$, kadar TSS tertinggi $56,34 \mathrm{mg} / \mathrm{L}$ terendah 40,23 , kadar $\mathrm{pH}$ tertinggi 6,38 terendah 5,20 . Hotel bintang 4 kadar $\mathrm{BOD}_{5}$ tertinggi $60,66 \mathrm{mg} / \mathrm{L}$ terendah $12 \mathrm{mg} / \mathrm{L}$, kadar COD tertinggi 80,45 mg/L terendah $24 \mathrm{mg} / \mathrm{L}$, kadar TSS tertinggi $56,38 \mathrm{mg} / \mathrm{L}$ terendah $20,4 \mathrm{mg} / \mathrm{L}$, kadar $\mathrm{pH}$ tertinggi 6,54 terendah 6,22 . Hotel bintang 5 kadar $\mathrm{BOD}_{5} 10 \mathrm{mg} / \mathrm{L}$, kadar COD $24 \mathrm{mg} / \mathrm{L}$, kadar TSS 54,34 mg/L dan pH 6,8.

Data analisis kualitas limbah cair hotel yang diperoleh dari Badan Lingkungan Hidup (BLH) Kota Pekanbaru sebagai data pembanding antara saat penelitian sedang dilaksanakan dengan data sebelum penelitian dapat dilihat pada Tabel 5 .

Tabel 5. Perbandingan hasil analisis kualitas air limbah cair hotel yang dilaporkan ke BLH Kota Pekanbaru dengan hasil analisis laboratorium pada saat penelitian

\begin{tabular}{cllllllll}
\hline & \multicolumn{3}{c}{ Data dari Hotel } & \multicolumn{5}{c}{ Data Analisis Laboratorium } \\
\cline { 2 - 9 } Hotel & \multicolumn{3}{c}{ Outlet } & \multicolumn{5}{c}{ Outlet } \\
& BOD $_{5}$ & COD & TSS & $\mathrm{pH}$ & BOD $_{5}$ & COD & TSS & $\mathrm{pH}$ \\
A1 & 20 & 36 & 53 & 6,50 & 20 & 42 & 48,36 & 6,30 \\
A2 & 22 & 40 & 51 & 5,50 & 32 & 40 & 51,38 & 5,20 \\
A3 & 6,20 & 20,60 & 32 & 6,38 & 4 & 8 & 56,34 & 6,38 \\
A4 & 21,20 & 66,40 & 57 & 6,10 & 22 & 36 & 50 & 6,20 \\
A5 & 18 & 28 & 53 & 5,90 & 30 & 72 & 54,40 & 5,90 \\
A6 & 121 & 723 & 43 & 5,90 & 40,02 & 55,50 & 40,23 & 5,90 \\
B1 & 45 & 65 & 43 & 6,20 & 12 & 24 & 56,38 & 6,22 \\
B2 & 18,50 & 80,40 & 17 & 6,74 & 40,24 & 60 & 25 & 6,48 \\
B3 & 73,30 & 509 & 12 & 6,86 & 60,66 & 80,45 & 20,40 & 6,54 \\
C1 & 10,20 & 53,60 & 10 & 6,90 & 10 & 24 & 54,34 & 6,80 \\
KepMen No. & 30 & 50 & 50 & $6-9$ & 30 & 50 & 50 & $6-9$ \\
52/MENLH10/1995 & & & & & & & & \\
\hline
\end{tabular}

Keterangan : $A 1-A 6=$ hotel bintang 3, B1-B3= Hotel bintang $4, C 1=$ hotel bintang 5

Bila dibandingkan hasil analisis IPLC hotel dengan Standar Baku Mutu Limbah Cair Hotel menurut Keputusan Menteri Negara Lingkungan Hidup No. 52/MENLH/10/1995, rata-rata hotel yang menjadi sampel pada penelitian ini kadar polutannya masih diatas standar baku mutu. Dari pengamatan dan wawancara langsung peneliti dilapangan dengan pihak hotel masih terdapat IPLC hotel yang belum bekerja dengan baik. Kerusakan IPLC disaluran inlet dan outlet menjadi pemicu utama tingginya nilai kualitas limbah cair. Hal ini akan berpengaruh terhadap efektivitas penerapan Keputusan Menteri Negara Lingkungan Hidup No. 52/MENLH/10/1995 tentang standar baku mutu limbah cair hotel.

\section{Teknik Pengolahan Limbah Cair Hotel}

Teknik atau sistem pengolahan limbah yang digunakan masing-masing hotel di lokasi penelitian secara umum menggunakan sistem resapan dan STP (Tabel 6). 
Tabel 6. Keadaan sistem pengolahan limbah, petugas operator dan kebocoran pada masing-masing hotel di Kota Pekanbaru

\begin{tabular}{cccc}
\hline Hotel & Sistem yang Digunakan & Petugas Operator (orang) & Kebocoran \\
\hline A1 & Resapan & 1 & Ada sedikit \\
A2 & Resapan & 1 & Ada sedikit \\
A3 & STP & 1 & Ada sedikit \\
A4 & STP & 1 & Ada sedikit \\
A5 & STP & 1 & Ada sedikit \\
A6 & STP & 1 & Ada sedikit \\
B1 & STP dan resapan & 2 & Ada sedikit \\
B2 & STP dan resapan & 2 & Ada sedikit \\
B3 & STP dan resapan & 2 & Ada sedikit \\
C1 & STP dan Resapan & 2 & Ada sedikit \\
\hline
\end{tabular}

\section{Sumber : Data Primer 2015}

Keterangan : $A 1-A 6=$ hotel bintang 3, B1-B3= Hotel bintang 4, $C 1=$ hotel bintang 5

$S T P=$ sewage treatment plan

Dari hasil wawancara dan observasi langsung ke IPLC hotel, seluruh hotel mengalami kebocoran dimana kebocoran tersebut pada sambungan elbo pipa yang disebabkan oleh penggumpalan lemak dari air buangan. Dari segi petugas operator IPLC, hotel bintang 3 hanya memiliki 1 operator, bintang 4 dan 5 masing-masing 2 operator. Jika ditinjau dari sistem waktu dan kapasitas limbah yang dihasilkan tiap hari sangat kurang disamping itu pengalaman ilmu pengetahuan dibidang IPLC operator hanya berbekal dari tempat hotel lama mereka bekerja.Hasil survey peneliti, pengolahan limbah hotel di Kota Pekanbaru menggunakan sistem STP kimia dan biologi.

\section{Efektivitas Keputusan Menteri Negara Lingkungan Hidup No.52/MENLH/10/1995}

Efektivitas pengolahan limbah cair hotel adalah kemampuan IPLC hotel-hotel dalam mereduksi kandungan polutan dalam limbah cair dan sebagai tolak ukurnya adalah hasil analisis kualitas air yang diambil dari IPLC inlet dan outlet serta laporan tahunan yang disampaikan pada Badan Lingkungan Hidup Kota Pekanbaru. Selain itu dihitung kadar limbah cair dan rata-rata hitungnya, presentase sampel yang memenuhi standar dan tingkat efektivitas IPLC yang ada (Martono, et al 2006), sehingga didapatkan kemampuan IPLC hotel-hotel dalam mereduksi kandungan polutan-polutan dalam limbah cair untuk parameter-parameter BOD, COD, TSS dan $\mathrm{pH}$ sebesar 72\%, 75\%, 25\% dan 16\% (Tabel 7).

Tabel 7. Tingkat penurunan kandungan polutan dalam limbah cair hotel di Kota Pekanbaru.

\begin{tabular}{|c|c|c|c|c|c|c|c|c|c|c|c|c|}
\hline \multirow{3}{*}{ Hotel } & \multicolumn{12}{|c|}{ Kandungan Polutan Limbah Cair Hotel } \\
\hline & \multicolumn{3}{|c|}{ BOD5 (mg/L) } & \multicolumn{3}{|c|}{$\mathrm{COD}(\mathrm{mg} / \mathrm{L})$} & \multicolumn{3}{|c|}{$\mathrm{TSS}(\mathrm{mg} / \mathrm{L})$} & \multicolumn{3}{|c|}{$\mathrm{pH}$} \\
\hline & Inlet & outlet & $\Delta \%$ & Inlet & outlet & $\Delta \%$ & Inlet & outlet & $\Delta \%$ & Inlet & outlet & $\Delta \%$ \\
\hline A1 & 200 & 20 & 90,00 & 360 & 42 & 88,30 & 54,36 & 48,36 & 11,0 & 5,21 & 6,30 & 0,90 \\
\hline $\mathrm{A} 2$ & 182 & 32 & 82,40 & 220 & 40 & 81,80 & 56,32 & 51,38 & 8,80 & 5,08 & 5,20 & 2,40 \\
\hline A3 & 84 & 4 & 95,20 & 120 & 8 & 93,30 & 61,34 & 56,34 & 8,20 & 6,01 & 6,38 & 6,20 \\
\hline A4 & 180 & 22 & 87,80 & 400 & 36 & 91,00 & 59,36 & 50 & 15,80 & 5,22 & 6,20 & 18,8 \\
\hline A5 & 320 & 30 & 90,60 & 680 & 72 & 89,40 & 82,20 & 54,40 & 33,80 & 5,11 & 6,00 & 17,4 \\
\hline A6 & 220 & 40,02 & 81,80 & 720 & 55,50 & 92,30 & 75,46 & 40,23 & 46,70 & 5,55 & 6,00 & 8,10 \\
\hline B1 & 56,22 & 12 & 78,70 & 90,28 & 24 & 73,40 & 52,38 & 56,38 & 7,10 & 4,80 & 6,22 & 29,6 \\
\hline
\end{tabular}




\begin{tabular}{|c|c|c|c|c|c|c|c|c|c|c|c|c|}
\hline \multirow[b]{3}{*}{$\overline{\mathrm{B} 2}$} & \multirow{2}{*}{\multicolumn{2}{|c|}{$\begin{array}{l}\text { JURNAL } \\
\text { (1) }\end{array}$}} & \multicolumn{5}{|c|}{ Volume 1, Nomor 1, 1-8, 2017} & \multicolumn{5}{|c|}{ ISSN: 2502-6496 (Print) } \\
\hline & & & & \multicolumn{9}{|c|}{ Syafri Boy et al., 2017. Efektivitas pengolahan limbah cair ... } \\
\hline & 112 & 40,24 & 64,10 & 280 & 60 & 78,60 & 80,23 & 25 & 68,80 & 5,20 & 6,48 & 24,6 \\
\hline B3 & 90,4 & 60,66 & 32,90 & 158,3 & 80,45 & 49,20 & 90,24 & 20,40 & 77,40 & 5,00 & 6,54 & 30,8 \\
\hline $\mathrm{C} 1$ & 102 & 10 & 90,20 & 320 & 24 & 92,50 & 55,32 & 54,34 & 1,80 & 6,02 & 6,80 & 13,0 \\
\hline rerata & 141 & 25 & 72 & 304 & 40 & 75 & 61 & 42 & 25 & 5 & 6 & 16 \\
\hline & & & $\Delta \%$ & $\begin{array}{l}\text { Sumb } \\
=\text { hote }\end{array}$ & 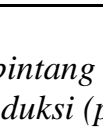 & $\begin{array}{l}: D c \\
B 1\end{array}$ & $\begin{array}{l}\text { Prime } \\
=H\end{array}$ & $\begin{array}{l}15 \\
\text { binto }\end{array}$ & $\begin{array}{l}\text { 4, } C \\
\text { itan }\end{array}$ & & ang & \\
\hline
\end{tabular}

Dari Tabel 7. pada outlet masih ada beberapa kadar polutan yang belum memenuhi standar baku mutu. Kisaran kandungan BOD pada inlet sebesar 56,22-320 mg/L dengan nilai rata-rata sebesar 141 $\mathrm{mg} / \mathrm{L}$. Tingkat kemampuan IPLC dalam mereduksi kandungan BOD sebesar 32,9-95\% dengan nilai ratarata sebesar $72 \%$, sehingga diperoleh hasil kinerja IPLC terhadap tingkat kandungan BOD pada titik outlet yang terjadi pada kisaran $4-60,66 \mathrm{mg} / \mathrm{L}$ dengan rata-rata $25 \mathrm{mg} / \mathrm{L}$. Kisaran kandungan COD pada titik inlet sebesar 90,28-720 mg/L dengan nilai rata-rata sebesar $304 \mathrm{mg} / \mathrm{L}$. Tingkat kemampuan IPLC dalam mereduksi kandungan COD sebesar 49,2-93,3\% dengan nilai rata-rata sebesar 75\%, sehingga diperoleh hasil kinerja IPLC terhadap tingkat kandungan COD pada titik outlet yang terjadi pada kisaran 8-80,45 $\mathrm{mg} / \mathrm{L}$ dengan rata-rata $40 \mathrm{mg} / \mathrm{L}$.Kisaran kandungan TSS pada titik inlet sebesar 54,36-90,24 mg/L dengan nilai rata-rata sebesar $61 \mathrm{mg} / \mathrm{L}$. Tingkat kemampuan IPLC dalam mereduksi kandungan BOD sebesar 1,8$77,4 \%$ dengan nilai rata-rata sebesar $25 \%$, sehingga diperoleh hasil kinerja IPLC terhadap tingkat kandungan TSS pada titik outlet yang terjadi pada kisaran 20.40-56,34 mg/L dengan rata-rata 41 $\mathrm{mg} / \mathrm{L}$.Kisaran kandungan $\mathrm{pH}$ pada titik inlet sebesar 5-6,02 dengan nilai rata-rata sebesar 5. Tingkat kemampuan IPLC dalam mereduksi kandungan $\mathrm{pH}$ sebesar 2,4-30,8\% dengan nilai rata-rata sebesar 16\%, sehingga diperoleh hasil kinerja IPLC terhadap tingkat kandungan $\mathrm{pH}$ pada titik outlet yang terjadi pada kisaran 5,20-6,80 dengan rata-rata 6.

Pemeriksaan BOD diperlukan untuk menentukan beban pencemaran akibat air buangan penduduk dan industri.BOD merupakan indikator pencemaran penting dalam air limbah. Tingginya kadar BOD pada tiap hotel disebabkan besarnya daya cemar air limbah. Menurut Duncan dan Sandy Cairncross dalam Matram, (1994), BOD akan semakin tinggi jika derajat pengotoran limbah semakin besar. Penguraian zat organik adalah peristiwa alamiah, jika badan air dicemari oleh zat organik, bakteri menghabiskan oksigen terlarut dalam air selama proses oksidasi tersebut yang bisa mengakibatkan kematian organisme akuatik dalam air dan keadaan menjadi anaerob sehingga dapat menimbulkan bau busuk pada air. Dari pantauan peneliti semua sampel limbah cair hotel di bagian inlet berbau busuk yang sangat menyengat.Chemical Oxygen Demand (COD)yaitu suatu uji yang menentukan jumlah oksigen yang dibutuhkan oleh bahan organik, untuk mengoksidasi bahan-bahan organik dalam 1 liter air dimana pengoksidasi $\mathrm{K}_{2} \mathrm{Cr}_{2} \mathrm{O}_{7}$ digunakan sebagai sumber oksigen. Angka COD merupakan ukuran bagi pencemaran air oleh zat-zat organik secara alamiah dapat dioksidasikan melalui proses mikrobiologis dan mengakibatkan berkurangnya oksigen terlarut di dalam air (Alaerts dan Santika, 1984).Penyebab utama terjadinya TSS adalah bahan anorganik berupa ion-ion yang umum dijumpai diperairan.Sebagai contoh air buangan sering mengandung molekul sabun, deterjen dan surfaktan yang larut air. Nilai TSS semakin tinggi dapat mempengaruhi turbiditas (kekeruhan) pada perairan, selain itu juga dapat mempengaruhi kehidupan akuatik karena jika turbiditas terus bertambah maka oksigen dan cahaya matahari terhalang masuk kedalam perairan sehingga mengganggu proses fotosintesis bagi kehidupan akuatik.Kadar TSS yang tinggi pada sampel limbah outlet, secara langsung akan berpengaruh terhadap berbagai parameter lainnya, yang berperan pada suatu perairan, sehingga berdampak pada rendahnya proses fotosintesis, hal ini akan mempengaruhi kadar oksigen terlarut dalam perairan (Riza, 2012) $\mathrm{pH}$ Konsentrasi ion Hidrogen merupakan salah satu parameter yang penting baik bagi air alamiah maupun air limbah. Oleh karena itu pH sering digunakan sebagai indikator untuk menyatakan baik buruknya suatu perairan (Fardiaz, 1992). Kadar $\mathrm{pH}$ pada sampel outlet relatif sudah memenuhi baku mutu. Rentang $\mathrm{pH}$ yang sesuai bagi kelangsungan hidup sebagian besar kehidupan biologis memiliki nilai 6-9. Air limbah yang memiliki konsentrasi ion Hidrogen yang ekstrim akan sulit ditangani oleh proses pengolahan biologis, dan jika konsentrasi ion Hidrogen ini tidak diubah terlebih dahulu sebelum dibuang ke lingkungan, maka air buangan ini dapat mengubah konsentrasi ion hidrogen pada badan air dilingkungan.

Ditinjau dari tingkat kemampuan IPLC hotel dalam menurunkan kadar parameter sampel limbah cair hotel yang tidak memenuhi persyaratan $(\mathrm{T})$ baku mutu menjadi limbah yang memenuhi syarat $(\mathrm{M})$ pada titik outlet untuk ke empat parameter tersebut juga tidak sama. Penilaian ini pada dasarnya dilakukan 
dengan menghitung selisih jumlah antara jumlah sampel yang tidak memenuhi syarat di titik inlet dengan parameter yang sama dititik outlet, untuk masing-masing parameter. Nilai yang diperoleh kemudian dibandingkan dengan jumlah sampel yang tidak memenuhi syarat di titik inlet, maka akan didapat proporsi penurunan jumlah sampel yang tidak memenuhi syarat untuk tiap-tiap parameter (Martono, et al 2006). Untuk lebih jelasnya dapat dilihat pada Tabel 8.

Tabel.8. Tingkat efektivitas IPLC hotel-hotel di Kota Pekanbaru Tahun 2015

\begin{tabular}{|c|c|c|c|c|c|c|c|c|}
\hline \multirow[t]{3}{*}{ Hotel } & \multicolumn{8}{|c|}{ Kondisi Parameter (memenuhi syarat/tidak memenuhi syarat) } \\
\hline & \multicolumn{2}{|c|}{ BOD5 } & \multicolumn{2}{|c|}{ COD } & \multicolumn{2}{|c|}{ TSS } & \multicolumn{2}{|c|}{$\mathrm{pH}$} \\
\hline & Inlet & outlet & Inlet & Outlet & Inlet & Outlet & Inlet & outlet \\
\hline A1 & $\mathrm{T}$ & M & $\mathrm{T}$ & $\mathrm{T}$ & $\mathrm{T}$ & M & $\mathrm{T}$ & M \\
\hline $\mathrm{A} 2$ & $\mathrm{~T}$ & $\mathrm{~T}$ & $\mathrm{~T}$ & $\mathrm{~T}$ & $\mathrm{~T}$ & $\mathrm{~T}$ & $\mathrm{~T}$ & $\mathrm{~T}$ \\
\hline A3 & $\mathrm{T}$ & M & $\mathrm{T}$ & M & $\mathrm{T}$ & $\mathrm{T}$ & M & M \\
\hline A4 & $\mathrm{T}$ & M & $\mathrm{T}$ & $\mathrm{T}$ & $\mathrm{T}$ & $\mathrm{M}$ & $\mathrm{T}$ & M \\
\hline A5 & $\mathrm{T}$ & $\mathrm{M}$ & $\mathrm{T}$ & $\mathrm{T}$ & $\mathrm{T}$ & $\mathrm{T}$ & $\mathrm{T}$ & $\mathrm{M}$ \\
\hline A6 & $\mathrm{T}$ & $\mathrm{T}$ & $\mathrm{T}$ & $\mathrm{T}$ & $\mathrm{T}$ & $\mathrm{M}$ & $\mathrm{T}$ & $\mathrm{M}$ \\
\hline B1 & $\mathrm{T}$ & $\mathrm{M}$ & $\mathrm{T}$ & $\mathrm{M}$ & $\mathrm{T}$ & $\mathrm{T}$ & $\mathrm{T}$ & $\mathrm{M}$ \\
\hline B2 & $\mathrm{T}$ & $\mathrm{T}$ & $\mathrm{T}$ & $\mathrm{T}$ & $\mathrm{T}$ & $\mathrm{M}$ & $\mathrm{T}$ & $\mathrm{M}$ \\
\hline B3 & $\mathrm{T}$ & $\mathrm{T}$ & $\mathrm{T}$ & $\mathrm{T}$ & $\mathrm{T}$ & $\mathrm{M}$ & $\mathrm{T}$ & M \\
\hline \multirow[t]{3}{*}{$\mathrm{C} 1$} & $\mathrm{~T}$ & $\mathrm{M}$ & $\mathrm{T}$ & $\mathrm{M}$ & $\mathrm{T}$ & $\mathrm{T}$ & $\mathrm{M}$ & $\mathrm{M}$ \\
\hline & $10 \mathrm{~T}, 0 \mathrm{M}$ & $4 \mathrm{~T}, 6 \mathrm{M}$ & $10 \mathrm{~T}, 0 \mathrm{M}$ & 7T,3M & $\begin{array}{c}10 \\
\mathrm{~T}, 0 \mathrm{M}\end{array}$ & $5 \mathrm{~T}, 5 \mathrm{M}$ & $8 \mathrm{~T}, 2 \mathrm{M}$ & $1 \mathrm{~T}, 9 \mathrm{M}$ \\
\hline & \multicolumn{2}{|c|}{$6 \mathrm{~T}(60,0 \%)$} & \multicolumn{2}{|c|}{$3 \mathrm{~T}(30,0 \%)$} & \multicolumn{2}{|c|}{$5 \mathrm{~T}(50,0 \%)$} & \multicolumn{2}{|c|}{$7 \mathrm{~T}(87,5 \%)$} \\
\hline
\end{tabular}

Sumber : Data Primer 2015

Keterangan : $A 1-A 6=$ hotel bintang 3, B1-B3= Hotel bintang $4, C 1=$ hotel bintang 5

$T=$ tidak memenuhi syarat

$M=$ memenuhi syarat

Dengan demikian efektivitas IPLC dalam menurunkan kadar limbah cair hotel di Pekanbaru yang memenuhi syarat untuk parameter-parameter BOD, COD,TSS dan $\mathrm{pH}$ masing-masing $60,0 \%, 30,0 \%$, $50,0 \%$ dan $87,5 \%$. Dari perhitungan diatas diketahui bahwa kemampuan IPLC hotel yang terbesar dalam meningkatkan kualitas limbah cair pada parameter $\mathrm{pH}$ yaitu sebesar 87,5\%. Sedangkan tingkat kemampuan terkecil terjadi pada COD sebesar 30\% sehingga pengolahan limbah cair hotel di Pekanbaru belum sepenuhnya efektif sesuai dengan Keputusan Menteri Lingkungan Hidup No. 52/MENLH/10/1995.

\section{Implementasi Keputusan Menteri Negara Lingkungan Hidup No.52/MENLH/10/1995}

Dari hasil analisis efektivitas pengolahan limbah cair hotel di Kota Pekanbaru menunjukkan Keputusan Menteri Negara Lingkungan Hidup No. 52/MENLH/10/1995belum terimplementasi oleh pengusaha hotel yang berada di Kota Pekanbaru.Jika dilihat dari Tabel 8.T (tidak memenuhi syarat) dan M (memenuhi syarat) pada bagian outlet, belum semuanya limbah cair hotel masuk pada kategori memenuhi syarat. Hal ini disebabkan masih tingginya kadar polutan yang berada pada instalasi pengolahan limbah cair (IPLC) outlet

\section{KESIMPULAN}

Efektivitas pengolahan limbah cair hotel di Kota Pekanbaru terhadap Keputusan Menteri Negara Lingkungan Hidup No. 52/MENLH/10/1995belum sepenuhnya efektif. Hal ini dapat dilihat dari kemampuan IPLC hotel-hotel dalam mereduksi kandungan polutan-polutan dalam limbah cair untuk 
parameter-parameter BOD, COD, TSS dan $\mathrm{pH}$ sebesar $72 \%, 75 \%, 25 \%$ dan $16 \%$, sedangkan efektivitas IPLC dalam menurunkan kadar limbah cair hotel di Pekanbaru yang memenuhi syarat untuk parameterparameter BOD, COD,TSS dan $\mathrm{pH}$ masing-masing 60,0\%, 30,0\%, 50,0\% dan 87,5\%. Untuk implemantasi Keputusan Menteri Negara Lingkungan Hidup No.52/MENLH/10/1995 tentang Baku Mutu Limbah Cair Hotel ternyata belum terimplementasi oleh pengusaha hotel yang berada di Kota Pekanbaru. Hal ini disebabkan masih tingginya kadar polutan yang berada pada instalasi pengolahan limbah cair (IPLC) outlet.

\section{UCAPAN TERIMAKASIH}

Penulis mengucapkan terimakasih kepada Allah SWT atas rahmat Nya, sehingga penelitian ini terlaksana dengan baik. Demikian pula atas dukungan semua pihak yang berkaitan dengan penelitian ini.

\section{DAFTAR PUSTAKA}

Agul. 2012. Warga Pekanbaru Waspadai Limbah Rumah Sakit dan Hotel. http://kilasriau.blogspot.com. Diakses 1 Oktober 2014.

Alaerts, G dan S.S., Santika. 1984. Metode Penelitian Air. Usaha Nasional. Surabaya.

Fardiaz, S. 1992. Polusi Air dan Udara. Kanisius. Yogyakarta.

Menteri Lingkungan Hidup. 1995. Keputusan Menteri Lingkungan Hidup Nomor 52/MENLH/10/1995 Tentang Baku Mutu Limbah Cair Bagi Kegiatan Hotel. Jakarta.

Martono, H. N, Besmanto. A, Anwar. Sukar. 2006. Tingkat Efektivitas Instalasi Pengolahan Limbah Cair Hotel-Hotel di Yogyakarta. Jurnal Ekologi Kesehatan. Vol. 34 No. 1.

Riza, N. 2012. Analisis Status Kualitas Air Anak-anak Sungai Singingi sekitar Tambang Batubara di Kuantan Singingi. Tesis, Program Pascasarjana Ilmu Lingkungan Universitas Riau (tidak diterbitkan).

Singarimbun, M dan S, Effendi. 2011. Metode Penelitian Survei. Lembaga Penelitian, Pendidikan dan Penerangan Ekonomi dan Sosial. Jakarta.

Sugiyono. 2011. Metode Penelitian Kuantitatif dan Kualitatif. Alfabeta. Bandung.

Yogi. 2014. Waduh, Pengelolaan Limbah Hotel pun Tidak Optimal. http://bertuahpos.com. Diakses 1 Oktober 2014. 